\title{
Behaviour of ${ }^{125} \mathrm{I}$-fibrinogen and ${ }^{131} \mathrm{I}$-albumin in experimental galactosamine-induced hepatitis ${ }^{1}$
}

\author{
I. MAHN, ${ }^{2}$ H. MERKEL, E. L. SATTLER, AND G. MƯLLER-BERGHAUS \\ From the Department of Medicine and Department of Nuclear Research, Central Division, Justus Liebig- \\ Universität, Giessen, Germany
}

SUMMARY The turnover of ${ }^{125}$ I-labelled fibrinogen and ${ }^{131}$ I-labelled albumin was studied in the course of galactosamine-induced hepatitis in rabbits. In addition to galactosamine, some animals were treated with epsilon-aminocaproic acid (EACA) to inhibit the activation of the fibrinolytic system. The infusion of galactosamine and EACA caused generation of fibrin-rich microclots in the renal glomerular capillaries in seven out of 12 rabbits. Correspondingly, the incorporation of ${ }^{125}$ I-radioactivity into liver, spleen, and kidneys was pronounced in galactosamine- and EACAtreated rabbits compared with control animals treated with EACA. An acceleration of the ${ }^{125}$ Ifibrinogen elimination from the plasma was observed between eight and 12 hours after the start of the galactosamine infusion. The administration of heparin in addition to galactosamine and EACA prevented the occurrence of intravascular coagulation, but shortened the survival times of the animals because of bleeding into visceral organs. The elimination of ${ }^{131}$ I-albumin in plasma as well as the distribution of ${ }^{131}$ I-radioactivity in organs were similar in all the rabbits independent of the treatment with galactosamine, EACA, or heparin. The experiments indicate that, in addition to diminished synthesis of coagulation factors, disseminated intravascular coagulation is involved in galactosamine-induced hepatitis and contributes to the haemostatic disorder.

Severe liver disease may be complicated by coagulation abnormalities. It is not yet established whether diminished synthesis or enhanced consumption of coagulation factors caused by disseminated intravascular coagulation (DIC) is responsible for the haemostatic disorder in liver failure (Bloom, 1975).

Studies in man indicate that DIC may be involved in the pathogenesis of liver disease (Verstraete et al., 1965; Lasch et al., 1967; Rake et al., 1970; Tytgat et al., 1971; Gallus et al., 1972, Hillenbrand et al., 1974). An experimental model of inducing acute hepatocellular injury in laboratory animals has only recently become available: the administration of D-galactosamine causes clinicopathological and

${ }^{1}$ Presented in part at the Vth Congress of the International Society on Thrombosis and Haemostasis, Paris, July 1975. Published as abstract: Thrombosis et Diathesis Haemorrhagica (1975), 34, 894.

'Present address: Section of Clinical Immunology and Blood Transfusion, Justus Liebig-Universität, Giessen, Germany

${ }^{3}$ Address for reprints and correspondence: Dr G. MüllerBerghaus, Department of Medicine, Klinikstr. 36, 63 Giessen, Germany

Received for publication 26 November 1976 histological alterations very similar to those observed in acute hepatic necrosis in man (Keppler et al., 1968; Reutter et al., 1968). If galactosamine was administered to rabbits, disseminated intravascular coagulation occurred, as evidenced by the tracing of fibrin-rich microclots in the renal glomerular capillaries (Müller-Berghaus and Reuter, 1972). The administration of EACA to galactosamine-infused rabbits increased the percentage of microclot formation. Heparin treatment prevented the occurrence of microclots after galactosamine administration (Müller-Berghaus et al., 1976).

The aim of this study was to investigate the alterations of the coagulation system after the application of D-galactosamine to rabbits in further detail. In order to differentiate between a defective hepatic synthesis of coagulation factors and disturbances in the coagulation system caused by disseminated intravascular coagulation the following investigations were performed: (1) coagulation analyses, (2) determination of the in vivo behaviour of ${ }^{125}$ I-fibrinogen and ${ }^{131}$ I-albumin, and (3) histological studies. 


\section{Methods}

\section{REAGENTS}

D-galactosamine- $\mathrm{HCl}$ From C. Roth, Karlsruhe, Germany, was dissolved in sterile, pyrogen-free distilled water and neutralised by adding sodium hydroxide.

Epsilon-aminocaproic acid (EACA) From Hoffmann-La Roche, Grenzach, Germany.

Heparin (Liqueminn 5000) From Hoffman-LaRoche, Grenzach, Germany.

${ }^{125}$ Iodine Without reducing agent from Hoechst, Frankfurt/M., Germany (specific activity 8-15 Ci 125I/mgI).

131 I-Human-albumin From Hoechst, Frankfurt/M., Germany (specific activity, $0.12 \mathrm{mCi} 131 \mathrm{I} / \mathrm{mg}$ albumin).

Aprotinin Protease inhibitor Trasylol from Bayer, Leverkusen, Germany.

Thrombin Topostasin, bovine thrombin, from Hoffmann-La Roche, Grenzach, Germany.

PREPARATION AND LABELLING OF RABBIT FIBRINOGEN

Rabbit fibrinogen was prepared from rabbit blood by glycine and ethanol precipitation as described in detail (Mahn and Müller-Berghaus, 1975). The precipitate was dissolved in sodium citrate $(0.055 \mathrm{M}$, $\mathrm{pH} \mathrm{7.4)}$ and adjusted to a protein concentration of $10 \mathrm{mg} / \mathrm{ml}$. The fibrinogen preparation revealed a clottability of $94 \%$. Labelling with ${ }^{125}$ I was performed according to the iodine monochloride method as described by McFarlane (1958). A mean ratio of 0.5 to 1.0 atoms iodine per molecule fibrinogen was achieved. Protein-bound radioactivity ranged from 98 to $99.5 \%$ determined by precipitating with trichloroacetic acid (TCA, $10 \% \mathrm{w} / \mathrm{v})$. Specific activity was about $50 \mu \mathrm{Ci} 125 \mathrm{I} / \mathrm{mg}$ protein. The clottability of fibrinogen after labelling with ${ }^{125}$ I remained unaltered.

\section{ANALYTICAL METHODS}

Fibrinogen was assayed according to the method of Jacobsson (1955) by clotting plasma with thrombin in the presence of disodium ethylenediaminetetraacetate (EDTA) and aprotinin. The thrombinclottable protein was dissolved in alkaline urea (6 $\mathrm{M}$ urea, $0.2 \mathrm{~N} \mathrm{NaOH}$ ). Measuring the optical density at $280 \mathrm{~nm}$ the concentration was computed by using the extinction coefficient: $\mathrm{E}_{1 \mathrm{~g} \%}^{1 \mathrm{~cm}}=16 \cdot 17$.

Platelets were counted directly by phase microscopy. Microhaematocrits were performed using heparinised tubes (Clay-Adams, New York, USA). Factor II and factor-V activities in plasma were assayed according to Schultze and Schwick (1953). The activated partial thromboplastin time was determined according to Proctor and Rapaport (1961) using commercially available reagents (BehringWerke, Marburg, Germany). The determination of glutamic-pyruvic transaminase (GPT) according to Wroblewski and LaDue (1956), serum bilirubin according to Jendrassik and Gróf (1938) were performed with commercial kits (C. F. Boehringer \& Söhne, Mannheim, Germany).

\section{RADIOISOTOPE TECHNIQUES}

125I- and 131I-activities were measured with a welltype gamma scintillation counter with two channel analyser (Friesecke-Höpfner, Erlangen, Germany) allowing simultaneous measurements of both isotopes. The following data were determined in $0.2 \mathrm{ml}$ samples each: total radioactivity in plasma (TA), clottable radioactivity (CA, radioactivity incorporated into the thrombin-induced fibrin clot), protein-bound activity (PA, after precipitation of plasma with TCA, final concentration $10 \% \mathrm{w} / \mathrm{v}$ ), and non-precipitable activity (NA, radioactivity remaining in the supernatant). All measurements were performed in duplicate. The radioclottability (RCB) of the 125I-fibrinogen preparation as well as of each plasma sample was calculated according to $\mathrm{RCB}=$ $\frac{\mathrm{CA}}{\mathrm{PA}} \times 100$ (Regoeczi, 1971). The clottable radioactivity (CA) of each plasma sample was expressed as percent of the initial value derived from the first blood sample immediately before starting infusions. Results were plotted on linear scale paper. In the same manner the protein-bound (PA) 131I-radioactivity in plasma representing the circulating 131I-albumin was analysed.

\section{DETERMINATION OF RADIOACTIVITIES IN ORGANS}

After death of the animals necropsies were performed immediately and 0.5 to $2.0 \mathrm{~g}$ of tissue were obtained for counting. The following organs were prepared: kidneys, liver, spleen, lungs, and psoas muscle. The results obtained as $\mathrm{cpm} / \mathrm{g}$ for each organ were expressed as a multiple of the psoas muscle counts $(\mathrm{cpm} / \mathrm{g}$ of psoas muscle $=1$ unit) using the radioactivity of this muscle as a reference standard for each animal.

All the concentrations as well as radioactivities determined in anticoagulated plasma samples were corrected for dilution of blood with a fluid anticoagulant as described elsewhere (Mahn and Müller-Berghaus, 1975). A correction for the withdrawal of blood and the resulting loss of radioactivity was not made. 


\section{HISTOLOGICAL STUDIES}

Organs were fixed in neutral $5 \%$ formalin. Sections were stained with haematoxylin and eosin, and fibrin was traced by the dimethyl-aminobenzaldehyde-nitrite reaction for the histochemical demonstration of tryptophan (Adams, 1957). In several kidney sections the immunofluorescence technique using anti-rabbit fibrinogen antiserum (Behringwerke, Marburg, Germany) was employed.

\section{ANIMALS}

Male and non-pregnant female rabbits of mixed New Zealand breeds weighing between 1.7 and 2.6 $\mathrm{kg}$ were used in this study. All the animals had free access to drinking water containing sodium iodide $(1 \mathrm{~g} / \mathrm{l})$.

Three days before injecting labelled ${ }^{125}$ I-fibrinogen and ${ }^{131} \mathrm{I}$-albumin a siliconised polyvinyl tube was inserted into the right jugular vein to ensure blood sampling over a longer period of time without anaesthesia. All the animals were injected with 125I-rabbit fibrinogen $(20-30 \mu \mathrm{Ci})$ and ${ }^{131}$ I-human albumin (20-30 $\mu \mathrm{Ci})$ dissolved in 1 to $2 \mathrm{ml}$ isotonic saline 48 hours before starting the experiments. Infusions were done through a polyethylene tube inserted into the marginal vein of the left ear. Blood $(10 \mathrm{ml})$ was drawn immediately before starting the infusion and four, eight, 12 and 24 hours thereafter. Anticoagulation was performed with one part of $3.8 \mathrm{~g} / 100 \mathrm{ml}$ sodium citrate containing $1000 \mathrm{KIU} / \mathrm{ml}$ aprotinin to nine parts of blood. Surviving animals were killed by an overdose of pentobarbital after the 24-hour blood sampling.

EXPERIMENTAL DESIGN

The rabbits were divided into four groups as follows (Fig. 1).

\section{Group A}

Twelve rabbits were intravenously injected with EACA $(1 \mathrm{~g} / \mathrm{kg})$ and consecutively infused with D-galactosamine $(1 \mathrm{~g} / \mathrm{kg})$ dissolved in $4.8 \mathrm{ml}$ isotonic saline over a period of 30 minutes. Thereafter, EACA $(0.5 \mathrm{~g} / \mathrm{kg} / \mathrm{h})$ was continuously infused until death.

\section{Group B}

Fifteen rabbits received galactosamine and EACA as the animals of group A. In addition, heparin was injected in a dose of $1500 \mathrm{U} / \mathrm{kg}$ before EACA injection and thereafter was continuously infused in a dose of $750 \mathrm{U} / \mathrm{kg} / \mathrm{h}$.

\section{Group C}

Eleven rabbits were injected and infused with EACA in the same dosage as above.

\section{Group D}

Ten rabbits served as controls and received isotonic saline only $(6 \mathrm{ml} / \mathrm{h})$.

All the animals received equal volumes of fluids by substituting the infusions of agents with isotonic saline. The infusions were performed by means of infusion pumps (Perfusor, Braun, Melsungen, Germany).

\section{STATISTICAL EVALUATION}

The results were subjected to the analysis of variance (partially hierarchical situations with three factors) and the Scheffé test (Scheffé, 1953). A value of less than $P=0.05$ was considered significant. The parameters measured were graphed as the arithmetical mean values of each group. Only the mean values are reported in this paper. Individual data can be obtained from the authors.

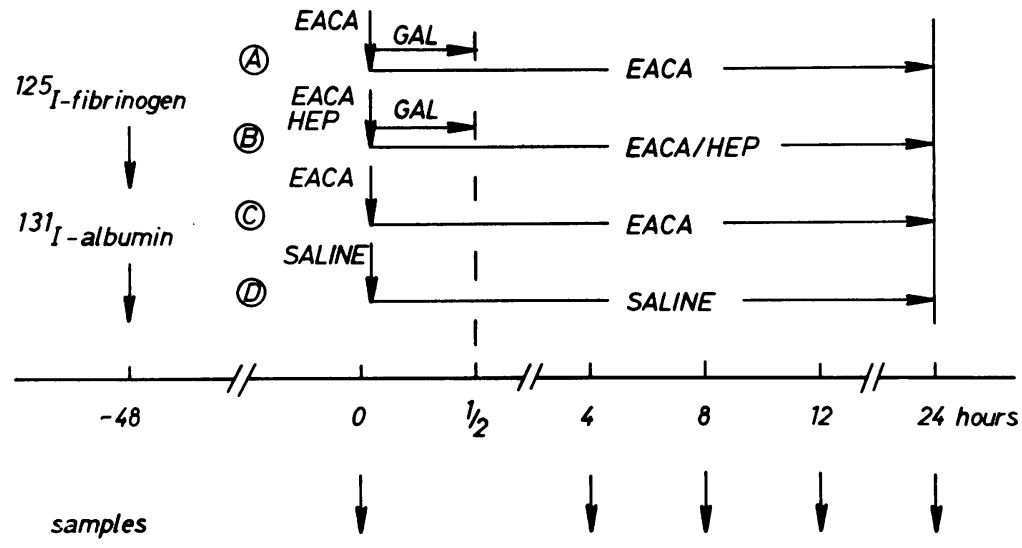

Fig. 1 Experimental design. 


\section{Results}

All the animals treated with galactosamine and EACA (group A) except one died between 12 and 24 hours after infusions had been started. If heparin was additionally infused (group B) only seven of 15 animals survived longer than 12 hours. Therefore, the data were subjected to statistical analysis only to the 12 hour sample. Animals which did not survive for 12 hours were excluded from statistics.

\section{STUDIES ON LIVER FUNCTION}

The induction of hepatitis was controlled by determining serum bilirubin and GPT. Both parameters changed significantly in comparison with those of the control groups (Fig. 2).

\section{HISTOLOGICAL STUDIES}

The livers of galactosamine-treated animals showed foci of hepatocellular necrosis disseminated throughout the lobules typical of galactosamine-induced hepatitis as described by Keppler et al. (1968).
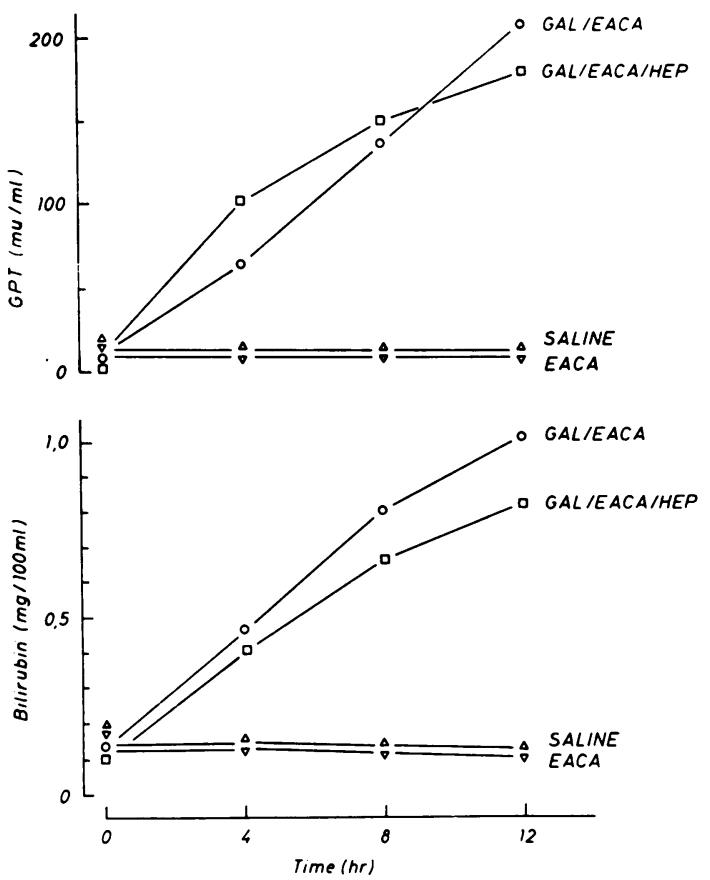

Fig. 2 Changes in mean serum glutamic-pyruvic transaminase (GPT) and serum bilirubin levels after infusion of D-galactosamine and epsilon-aminocaproic acid (GAL/ EACA), D-galactosamine, epsilon-aminocaproic acid and heparin (GAL/EACA/HEP), epsilon-aminocaproic acid (EACA), or isotonic saline (SALINE) into rabbits. The curves $G A L / E A C A$ and $G A L / E A C A / H E P$ differ significantly $(\mathrm{P}<0.001)$ from curves $E A C A$ and $S A L I N E$, respectively
Fibrin-rich microclots in the renal glomerular capillaries typical of the generalised Schwartzman reaction could be detected in seven of 12 rabbits which had received galactosamine and EACA (group A). In animals treated with heparin in addition to galactosamine and EACA (group B), glomerular microclots could not be detected (Table 1). Control rabbits receiving EACA (group C) or saline (group D) did not exhibit microclots.

125I-radioactivity was highest in organs of animals treated with galactosamine and EACA (Table 2). 125I-radioactivity incorporated into the lungs did not differ significantly between groups. The ${ }^{131}$ I-radioactivity was distributed equally in all the corresponding organs of the animals except for the lungs. 131I-radioactivity incorporated into lungs was about twice as high as that found in kidneys, liver, and spleen (Table 3).

\section{COAGULATION STUDIES}

As seen from Figs. 3 and 4 the partial thromboplastin time, prothrombin time activity, and factor-V activity of animals receiving galactosamine were markedly changed compared with the controls eight hours after having started the experiments.

The mean platelet counts expressed as percent of the initial values dropped significantly lower in animals receiving galactosamine than in control animals. But no significant difference could be computed between groups A and B, if heparin was infused additionally to galactosamine and EACA (Fig. 4).

The haematocrit values as well as the ${ }^{131}$ I-albumin activity in plasma decreased in all the animals in the course of the experiment. Significant differences between groups could not be detected. Therefore, haematological data were not corrected for in vivo haemodilution caused by the experimental procedure (Fig. 5).

Fibrinogen levels in plasma of animals treated with galactosamine and EACA (group A) decreased

Table I Incidence of fibrin-rich microclots in renal glomerular capillaries of rabbits infused with D-galactosamine (GAL), epsilon-aminocaproic acid (EACA), heparin (HEP), and isotonic saline (SALINE) in different combinations

\begin{tabular}{llll}
\hline Group & $\begin{array}{l}\text { Rabbits } \\
\text { (no.) }\end{array}$ & Treatment & $\begin{array}{l}\text { Incidence of } \\
\text { microclots in } \\
\text { glomerular } \\
\text { capillaries }\end{array}$ \\
\hline A & 12 & GAL/EACA & $7 / 12$ \\
B & 7 & GAL/EACA/HEP & $0 / 7$ \\
C & 11 & EACA & $0 / 11$ \\
D & 10 & SALINE & $0 / 10$ \\
\hline
\end{tabular}

* Number of animals with microclots over the toal number of rabbits studied 
Table 2 Distribution of ${ }^{125}$ I-radioactivity derived from labelled fibrinogen in organs of rabbits treated differently*

\begin{tabular}{|c|c|c|c|c|c|c|}
\hline Group & No. & Treatment & $\begin{array}{l}\text { Kidney } \\
(U / g)\end{array}$ & $\begin{array}{l}\text { Liver } \\
(U / g)\end{array}$ & $\begin{array}{l}\text { Spleen } \\
(U / g)\end{array}$ & $\begin{array}{l}\text { Lungs } \\
(U / g)\end{array}$ \\
\hline $\mathbf{A}$ & 12 & GAL/EACA & $\begin{array}{l}19 \cdot 9 \\
(3 \cdot 0-75 \cdot 9)\end{array}$ & $\begin{array}{l}35 \cdot 8 \\
(9 \cdot 2-70 \cdot 9)\end{array}$ & $\begin{array}{l}91 \cdot 9 \\
(14 \cdot 8-393 \cdot 7)\end{array}$ & $\begin{array}{l}10 \cdot 0 \\
(4 \cdot 2-17 \cdot 5)\end{array}$ \\
\hline B & 7 & GAL/EACA/HEP & $\begin{array}{l}6 \cdot 0 \\
(3 \cdot 5-8 \cdot 8)\end{array}$ & $\begin{array}{l}15 \cdot 4 \\
(5 \cdot 9-27 \cdot 5)\end{array}$ & $\begin{array}{l}55 \cdot 1 \\
(10 \cdot 7-140 \cdot 3)\end{array}$ & $\begin{array}{l}11 \cdot 3 \\
(4 \cdot 7-15 \cdot 2)\end{array}$ \\
\hline C & 11 & EACA & $\begin{array}{l}5 \cdot 4 \\
(2 \cdot 1-7 \cdot 0)\end{array}$ & $\begin{array}{l}14 \cdot 0 \\
(4 \cdot 2-40 \cdot 8)\end{array}$ & $\begin{array}{l}20 \cdot 5 \\
(3 \cdot 8-86 \cdot 0)\end{array}$ & $\begin{array}{l}24 \cdot 7 \\
(5 \cdot 1-48 \cdot 2)\end{array}$ \\
\hline D & 10 & SALINE & $\begin{array}{l}5 \cdot 7 \\
(4 \cdot 0-13 \cdot 2)\end{array}$ & $\begin{array}{l}12 \cdot 4 \\
(6 \cdot 8-23 \cdot 5)\end{array}$ & $\begin{array}{c}7 \cdot 8 \\
(4 \cdot 4-13 \cdot 1)\end{array}$ & $\begin{array}{l}14 \cdot 8 \\
(4 \cdot 9-23 \cdot 6)\end{array}$ \\
\hline
\end{tabular}

*(Abbreviations as in Table 1). Means and ranges (in parentheses) are listed as units per $1 \mathrm{~g}$ of tissue weight. 1 unit is the ${ }^{125}$ I-radioactivity incorporated into $1 \mathrm{~g}$ of psoas muscle $(\mathrm{cpm} / \mathrm{g}$ muscle $=1 \mathrm{U}$ ). Mean radioactivities incorporated into kidneys, liver, and spleen of group $\mathrm{A}$ differ significantly from those of the other groups. No significant differences were found between lungs of all four groups.

Table 3 Distribution of ${ }^{131}$-radioactivities derived from labelled albumin in organs of rabbits treated differently*

\begin{tabular}{|c|c|c|c|c|c|c|}
\hline Group & No. & Treatment & $\begin{array}{l}\text { Kidney } \\
(U / g)\end{array}$ & $\begin{array}{l}\text { Liver } \\
(U / g)\end{array}$ & $\begin{array}{l}\text { Spleen } \\
(U / g)\end{array}$ & $\begin{array}{l}\text { Lungs } \\
(U / g)\end{array}$ \\
\hline $\mathbf{A}$ & 12 & GAL/EACA & $\begin{array}{l}4 \cdot 1 \\
(0 \cdot 9-7 \cdot 2)\end{array}$ & $\begin{array}{l}3 \cdot 4 \\
(1 \cdot 9-4 \cdot 8)\end{array}$ & $\begin{array}{l}3 \cdot 2 \\
(2 \cdot 2-4 \cdot 8)\end{array}$ & $\begin{array}{l}6 \cdot 3 \\
(3 \cdot 5-9 \cdot 4)\end{array}$ \\
\hline B & 7 & GAL/EACA/HEP & $\begin{array}{l}3 \cdot 6 \\
(2 \cdot 0-5 \cdot 2)\end{array}$ & $\begin{array}{l}3 \cdot 5 \\
(2 \cdot 6-4 \cdot 8)\end{array}$ & $\begin{array}{l}2 \cdot 9 \\
(1 \cdot 9-4 \cdot 0)\end{array}$ & $\begin{array}{l}6 \cdot 5 \\
(3 \cdot 4-9 \cdot 4)\end{array}$ \\
\hline C & 11 & EACA & $\begin{array}{l}2 \cdot 9 \\
(1 \cdot 8-3 \cdot 7)\end{array}$ & $\begin{array}{l}4 \cdot 6 \\
(3 \cdot 1-6 \cdot 7)\end{array}$ & $\begin{array}{l}3 \cdot 3 \\
(1 \cdot 9-4 \cdot 7)\end{array}$ & $\begin{array}{l}7 \cdot 9 \\
(5 \cdot 4-10 \cdot 1)\end{array}$ \\
\hline D & 10 & SALINE & $\begin{array}{l}3 \cdot 4 \\
(1 \cdot 3-7 \cdot 7)\end{array}$ & $\begin{array}{l}5 \cdot 8 \\
(3 \cdot 4-8 \cdot 8)\end{array}$ & $\begin{array}{l}2 \cdot 7 \\
(1 \cdot 5-4 \cdot 5)\end{array}$ & $\begin{array}{l}8 \cdot 3 \\
(3 \cdot 8-13 \cdot 6)\end{array}$ \\
\hline
\end{tabular}

*(Abbreviations as in Table 1.) Means and ranges (in parentheses) are listed as units per $1 \mathrm{~g}$ of tissue weight. 1 unit is the ${ }^{131} \mathrm{I}-\mathrm{radioactivity}$ incorporated into $1 \mathrm{~g}$ of psoas muscle $(\mathrm{cpm} / \mathrm{g}$ muscle $=1 \mathrm{U}$ ). Statistical analysis did not reveal significant differences of corresponding organs between groups.

significantly in comparison with the control animals receiving EACA or saline $(P<0.01)$. Heparin administration in addition to galactosamine and EACA significantly reduced the drop in the plasma fibrinogen concentration at 12 hours after having started the infusions $(P<0.05)$ (Fig. 6).

If the elimination curve of 125I-fibrinogen of control animals infused with saline only (group D) is compared with the behaviour of the plasma fibrinogen concentrations of all four groups, the following observations can be made (Fig. 6). The elimination curve of ${ }^{125}$ I-fibrinogen almost parallels the course of the fibrinogen concentration in animals treated with galactosamine up to eight hours. At 12 hours after starting the experiments, the fibrinogen levels of animals treated with galactosamine and EACA drop below the elimination curve of ${ }^{125}$ I-fibrinogen of the control animals, whereas the fibrinogen levels of animals treated additionally with heparin remain above the elimination curve of 125I-fibrinogen. Control rabbits treated with EACA or saline, respectively, show only minor alterations in fibrinogen concentrations during the course of the experiment because of undisturbed synthesis of fibrinogen by the liver.

The elimination of ${ }^{125}$ I-fibrinogen from blood measured as the clottable radioactivity in plasma was uniform in all four groups up to eight hours after having started the infusions (Fig. 7). At 12 hours, however, ${ }^{125}$ I-fibrinogen activity in plasma of animals treated with galactosamine and EACA decreased significantly in comparison with the other groups $(P<0.001)$. Treatment with heparin in addition to galactosamine and EACA prevented this final drop of 125I-fibrinogen activity in plasma. At 12 hours the difference in ${ }^{125}$ I-fibrinogen activities between heparin-treated and untreated rabbits was significant at a level of $P<0.01$.

\section{Discussion}

D-galactosamine induces acute hepatocellular necrosis in experimental animals (Keppler et al., 1968; Reutter et al., 1968). The coagulation defects observed as characterised by the reduced level of plasma fibrinogen or the decrease in other coagulation factors in plasma may solely be explained by an impaired capacity of the liver to synthesise clotting factors. The finding of soluble fibrin in plasma and the detection of fibrin-rich microclots in the renal glomerular capillaries, however, indicate that disseminated intravascular coagulation may contribute to the coagulation disturbance. Besides, an increased activity of the fibrinolytic system in plasma may be 

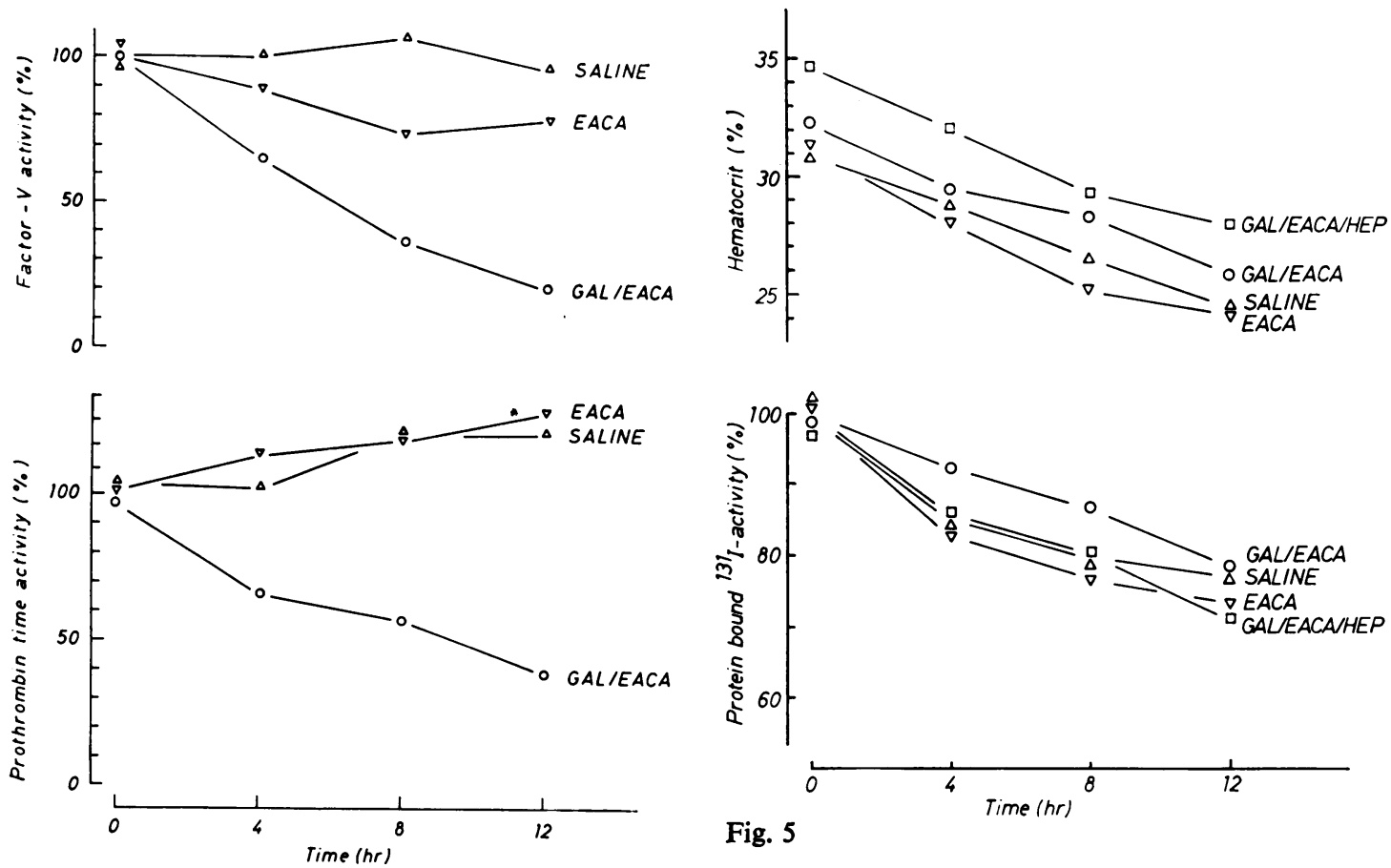

Fig. 3

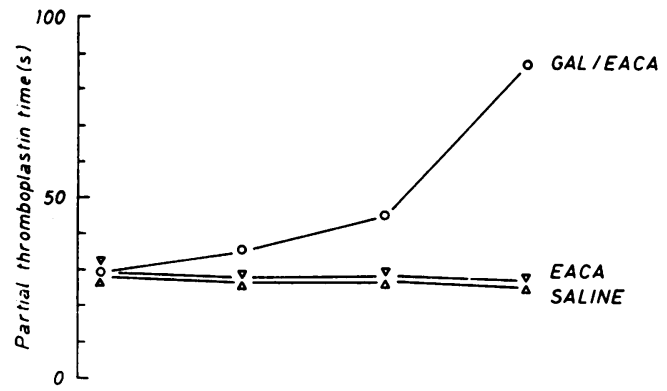

Fig. 5

Fig. 4

Fig. 3 Changes in mean factor-V activity and prothrombin activity after infusion of D-galactosamine and epsilonaminocaproic acid (GAL/EACA), epsilon-aminocaproic acid (EACA), or saline (SALINE) into rabbits. The curves $G A L / E A C A$ differ significantly $(\mathrm{P}<0.001)$ from curves EACA and SALINE, respectively.

Fig. 4 Changes in mean values of the partial thromboplastin time and mean platelet counts after infusion of D-galactosamine and epsilon-aminocaproic acid (GAL/ EACA), D-galactosamine, epsilon-aminocaproic acid and heparin (GAL/EACA/HEP), epsilon-aminocaproic acid $(E A C A)$, or saline (SALINE) into rabbits. The partial thromboplastin time of $G A L / E A C A$ differs significantly $(\mathrm{P}<0.001)$ from that of EACA and SALINE. Platelet counts of GAL/EACA and GAL/EACA/HEP differ significantly $(\mathrm{P}<0.001)$ from those of EACA or SALINE. No significant difference could be computed between GAL/EACA and GAL/EACA/HEP.

Fig. 5 Changes in mean haematocrit values and protein bound ${ }^{131}$ I-activity in plasma after infusion of D-galactosamine and epsilon-aminocaproic acid (GAL/EACA), D-galactosamine, epsilon-aminocaproic acid and heparin (GAL/EACA/HEP), epsilon-aminocaproic acid (EACA), or saline (SALINE) into rabbits. The curves of haematocrit values as well as the curves of protein bound ${ }^{131}$ I-activities do not differ significantly between groups.

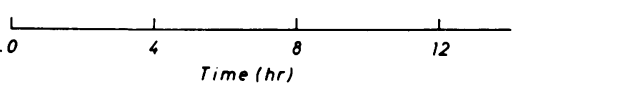




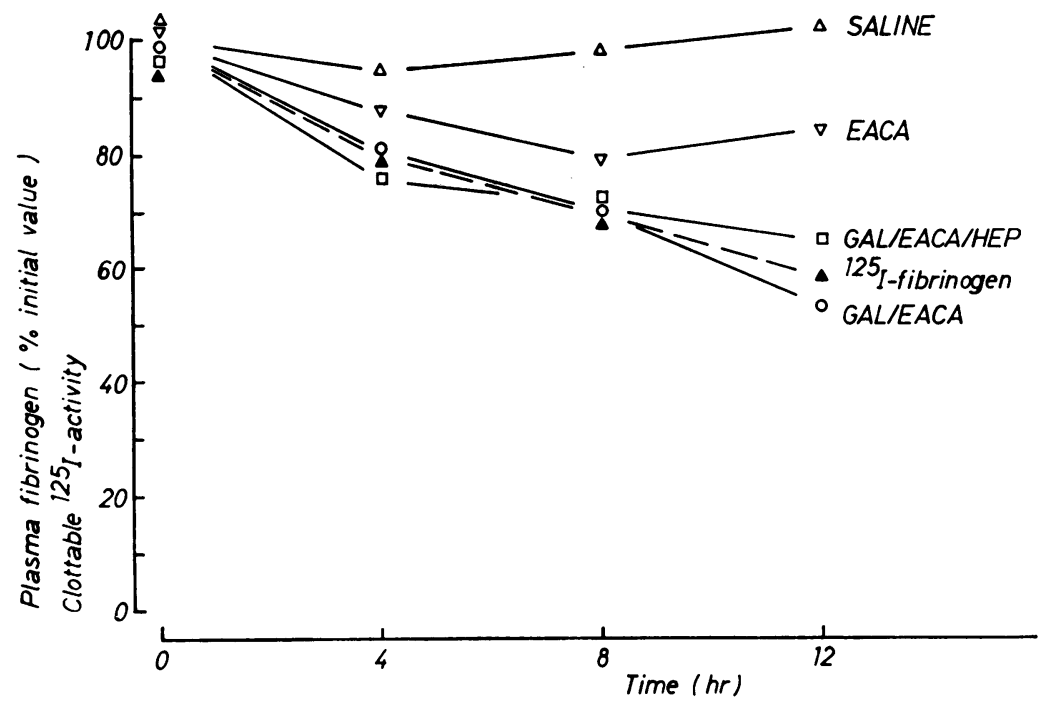

Fig. 6 Comparison of mean plasma fibrinogen levels after infusion of D-galactosamine, epsilon-aminocaproic acid $(G A L / E A C A)$, D-galactosamine, epsilon-aminocaproic acid and heparin (GAL/EACA/HEP), epsilon-aminocaproic acid $(E A C A)$, or saline (SALINE) into rabbits with the mean elimination curve of ${ }^{125}$ I-fibrinogen in control animals infused with saline ( ${ }^{125} I$-fibrinogen). The elimination curve of ${ }^{125} I$-fibrinogen parallels the curves of fibrinogen levels of groups $A(G A L / E A C A)$ and $B(G A L / E A C A \mid$ $H E P)$. The fibrinogen levels of group $A$ differ significantly $(\mathrm{P}<0.05)$ from that of group $B$ and both decrease significantly $(\mathrm{P}<0.001)$ compared with groups $C(E A C A)$ and $D(S A L I N E)$.

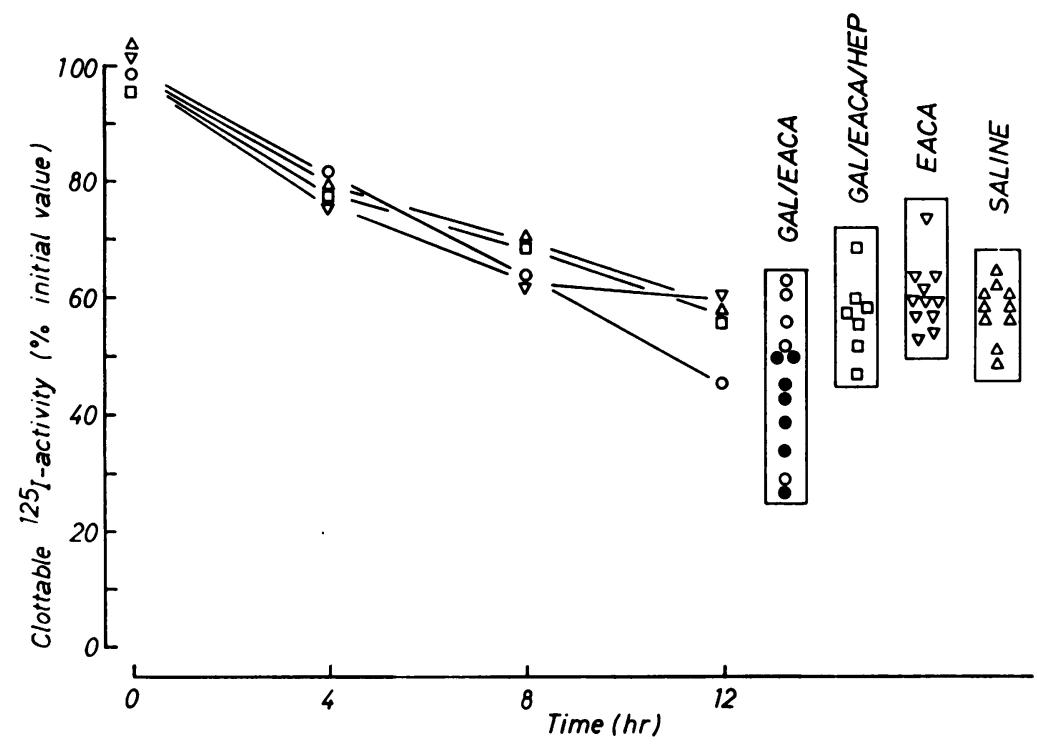

Fig. 7 Changes in mean values of plasma clottable ${ }^{125}$ I-activities after infusion of D-galactosamine and epsilon-aminocaproic acid (GAL/EACA), D-galactosamine, epsilon-aminocaproic acid and heparin $(G A L / E A C A / H E P)$, epsilon-aminocaproic acid (EACA), or saline (SALINE) into rabbits. Individual values of each animal 12 hours after having started infusions are grouped in columns. : animals showing renal glomerular microclots; $\bigcirc \triangle \square \nabla$ : animals without microclots. Mean clottable ${ }^{125}$ I-activity of group $A(G A L / E A C A)$ differs significantly ( $\left.\mathrm{P}<0.001\right)$ from those of the other groups at 12 hours. 
involved in the pathogenesis of liver disease and of the associated haemostatic failure. These controversial findings complicate the interpretation of laboratory data.

Turnover studies with labelled fibrinogen enable measurement of the catabolism of fibrinogen under normal and pathological conditions in vivo. As pointed out by Regoeczi (1970), the fractional catabolic rate is the most important parameter in describing fibrinogen metabolism. The fractional catabolic rate (FCR) is the part of the plasma fibrinogen pool catabolised per time unit. FCR may be increased by an enhanced cellular uptake of uninjured original fibrinogen, by an extracellular consumption caused by disseminated intravascular coagulation, by fibrinogenolysis, by degradation in pathological tissues, or merely by intra- or extracorporal bleeding. In the present study the FCR of fibrinogen was influenced homogeneously in all the rabbits by the intravenous infusion of agents and by blood sampling. As seen from the course of the haematocrit values and the decrease in ${ }^{131}$ I-activities representing the elimination of albumin (Fig. 5), the alterations are uniform in all four groups. Therefore, corrections of the activities of labelled fibrinogen in plasma because of haemodilution and blood sampling were not made and consequently the calculation of FCR did not seem to be suggestive. On the other hand, an increase in FCR can be registered by a pronounced decay of the elimination curve of labelled fibrinogen in plasma.

Purification and labelling of fibrinogen may alter the normal behaviour of this protein when reinjected into the body. But, as shown by McFarlane (1963) and Atencio et al. (1965a, b), the metabolic performance of radio-iodinated fibrinogen remains unaffected by the purification and labelling procedures used in this study. The clottability of the purified rabbit fibrinogen was not affected by the iodination procedure applied. ${ }^{125}$ I-fibrinogen was injected into rabbits 48 hours before experiments were started to ensure that any denatured material inherent in the preparation was eliminated within that time, and that an equilibrium of 125 I-fibrinogen between intra- and extravascular compartments was reached.

The decay of ${ }^{125}$ I-fibrinogen was uniform in all four groups up to eight hours after the start of the experiments. But 12 hours thereafter, the ${ }^{125} \mathrm{I}$ fibrinogen activity in plasma of animals treated with galactosamine and EACA dropped significantly in comparison with animals treated additionally with heparin to prevent activation of the coagulation system or to the control animals infused with EACA or saline, respectively. Treatment of the animals with EACA excluded the possibility that activation of fibrinogenolysis might influence the elimination of ${ }^{125} \mathrm{I}$-fibrinogen. The comparison of the elimination curve of ${ }^{125}$ I-fibrinogen in saline-infused control rabbits with the plasma fibrinogen concentrations of rabbits treated with galactosamine and EACA or galactosamine, EACA, and heparin proved the identical in vivo behaviour of the labelled fibrinogen and the native one. The present study shows that the synthesis of fibrinogen was completely blocked by galactosamine administration, as the decrease in plasma fibrinogen concentrations parallels the elimination of the labelled fibrinogen in control animals up to eight hours. The occurrence of fibrinrich microclots in renal glomerular capillaries and the accumulation of ${ }^{125}$ I-radioactivity in organs of galactosamine-treated animals as well as the prevention of these findings by heparin treatment confirm the evidence of disseminated intravascular coagulation in this experimental setup. The drop of the platelet counts after galactosamine and EACA administration was not prevented by heparin treatment. This drop of platelet counts may be caused by the aggregation of platelets upon contact with collagen exposed after galactosamine-induced tissue lesions. Obviously, the effect of the generation of intravascular thrombin on platelets was of minor importance, as heparin treatment did not overcome the decrease in platelet counts.

Our data show that the decrease in plasma fibrinogen concentration is caused by a diminished synthesis of coagulation factors in the early phase after application of galactosamine to rabbits. In the late phase, enhanced consumption of fibrinogen caused by disseminated intravascular coagulation contribute to the haemostatic disorder in this model of experimental hepatitis. Heparin prevented the activation of the plasmatic coagulation system and, thus, the formation of fibrin-rich capillary microclots. Heparin, however, shortened the survival times of the animals most probably because the rabbits died as a consequence of heparin-induced haemorrhages into visceral organs. These experimental findings support the concept of intravascular coagulation in patients with acute hepatitis (Rake et al., 1970; Gallus et al., 1972; Verstraete et al., 1974; Bloom, 1975). The potential benefit of heparin treatment in severe liver disease, however, seems to be doubtful.

This work was supported by the Deutsche Forschungsgemeinschaft, Bonn-Godesberg, Germany. The authors acknowledge the technical assistance of Mrs A. Chandoni.

\section{References}

Adams, C. W. M. (1957). A p-dimethylaminobenzaldehydenitrite method for the histochemical demonstration of tryptophane and related compounds. Journal of Clinical 
Pathology, 10, 56-62.

Atencio, A. C., Bailey, H. R., and Reeve, E. B. (1965a). Studies on the metabolism and distribution of fibrinogen in young and older rabbits. I. Methods and models. Journal of Laboratory and Clinical Medicine, 66, 1-19.

Atencio, A. C., and Reeve, E. B. (1965b). Studies on the metabolism and distribution of fibrinogen in young and older rabbits. 2. Results. Journal of Laboratory and Clinical Medicine, 66, 20-33.

Bloom, A. L. (1975). Intravascular coagulation and the liver. British Journal of Haematology, 30, 1-7.

Gallus, A. S., Lucas, C. R., and Hirsh, J. (1972). Coagulation studies in patients with acute infectious hepatitis. British Journal of Haematology, 22, 761-771.

Hillenbrand, P., Parbhoo, S. P., Jedrychowski, A., and Sherlock, S. (1974). Significance of intravascular coagulation and fibrinolysis in acute hepatic failure. Gut, 15, 83-88.

Jacobsson, K. (1955). Studies on the determination of fibrinogen in human blood plasma. Scandinavian Journal of Clinical and Laboratory Investigation, suppl., 14, 7-54.

Jendrassik, L., and Gróf, P. (1938). Vereinfachte photometrische Methoden zur Bestimmung des Blutbilirubins. Biochemische Zertschrift, 297, 81-89.

Keppler, D., Lesch, R., Reutter, W., and Decker, K. (1968). Experimental hepatitis induced by D-galactosamine. Experimental and Molecular Pathology, 9, 279-290.

Lasch, H-G., Heene, D. L., Huth, K., and Sandritter, W. (1967). Pathophysiology, clinical manifestations and therapy of consumption-coagulopathy ('Verbrauchskoagulopathie'). American Journal of Cardiology, 20, 381-391.

Mahn, I., and Müller-Berghaus, G. (1975). Studies on catabolism of ${ }^{125} \mathrm{I}$-labelled fibrinogen in normal rabbits and in rabbits with indwelling intravenous catheters: methodologic aspects. Haemostasis, 4, 41-50.

McFarlane, A. S. (1958). Efficient trace-labelling of proteins with iodine. Nature, 182, 53.

McFarlane, A. S. (1963). In vivo behaviour of $\mathbf{I}^{131}$-fibrinogen Journal of Clinical Investigation, 42, 346-361.

Müller-Berghaus, G., and Reuter, C. (1972). Disseminated intravascular coagulation in galactosamine-induced experimental hepatitis. Thrombosis Research, 1, 473-486.
Müller-Berghaus, G., Reuter, C., and Bleyl, U. (1976). Experimental galactosamine-induced hepatitis. Effect of anticoagulant and antifibrinolytic agents on microclot formation. American Journal of Pathology, 82, 393-406.

Proctor, R. R., and Rapaport, S. I. (1961). The partial thromboplastin time with kaolin. American Journal of Clinical Pathology, 36, 212-219.

Rake, M. O., Flute, P. T., Pannell, G., and Williams, R. (1970). Intravascular coagulation in acute hepatic necrosis. Lancet, 1, 533-537.

Rake, M. O., Flute, P. T., Pannell, G., Shilkin, K. B., and Williams, R. (1973). Experimental hepatic necrosis: studies on coagulation abnormalities, plasma clearance and organ distribution of ${ }^{125} \mathrm{I}$-labelled fibrinogen. Gut, 14, 574-580.

Regoeczi, E. (1970). Abnormal fibrinogen metabolism. In Plasma Protein Metabolism, pp. 459-479. Edited by M. A. Rothschild and T. Waldmann. Academic Press: New York.

Regoeczi, E. (1971). Iodine-labelled fibrinogen: a review. British Journal of Haematology, 20, 649-663.

Reutter, W., Lesch, R., Keppler, D., and Decker, K. (1968) Galaktosamin-Hepatitis. Naturwissenschaften, 55, 497.

Scheffé, H. (1953). A method for judging all contrasts in the analysis of variance. Biometrika, 40, 87-104.

Schultze, H. E., and Schwick, G. (1953). Die klinische Bedeutung der differenzierten Bestimmung von Prothrombin und Acceleratoren der Blutgerinnung (I). Medizinische, 2, 1354-1357.

Tytgat, G. N., Collen, D., and Verstraete, M. (1971). Metabolism of fibrinogen in cirrhosis of the liver. Journal of Clinical Investigation, 50, 1690-1701.

Verstraete, M., Vermylen, J., and Collen, D. (1974). Intravascular coagulation in liver disease. Annual Review of Medicine, 25, 447-455.

Verstraete, M., Vermylen, C., Vermylen, J., and Vandenbroucke, J. (1965). Excessive consumption of blood coagulation components as cause of hemorrhagic diathesis. American Journal of Medicine, 38, 899-908.

Wróblewski, F., and LaDue, J. S. (1956). Serum glutamicpyruvic transaminase in cardiac and hepatic disease. Proceedings of the Society for Experimental Biology, 91, 569-571. 